\title{
PENGARUH SENAM PROLANIS TERHADAP PENURUNAN KADAR GULA DARAH PENDERITA DIABETES MELITUS TIPE 2 PADA LANSIA DI PUSKESMAS BINUANG, POLMAN
}

\author{
Nurul Patima ${ }^{1}$, Darwis ${ }^{2}$, Hasanuddin ${ }^{3}$ \\ ${ }^{1}$ STIKES Nani Hasanuddin Makassar \\ ${ }^{2}$ STIKES Nani Hasanuddin Makassar \\ ${ }^{3}$ STIKES Nani Hasanuddin Makassar
}

Alamat Korespondensi : (nurul.patima21@gmail.com / 085397865863)

\begin{abstract}
ABSTRAK
Diabetes Melitus tipe 2 disebabkan oleh kurang sensitifnya jaringan tubuh terhadap insulin. Pankreas tetap menghasilkan insulin, kadang kadarnya lebih tinggi dari normal. Latihan fisik salah satunya senam prolanis yang berperan sebagai glicemic control yaitu mengatur dan mengendalikan kadar gula darah. Tujuan penelitian ini untuk mengetahui pengaruh senam prolanis terhadap penurunan kadar gula darah penderita diabetes melitus tipe 2 pada lansia di Puskesmas Binuang, Polman. Penelitian ini menggunakan one group pre-test and post-test design. Pengambilan sampel menggunakan purposive sampling. Di dapatkan 30 responden sesuai kriteria inklusi. Pengumpulan data dilakukan secara langsung dengan mengobservasi atau mengukur kadar gula darah sebelum dan sesudah intervensi dan analisis dengan menggunakan uji wilcoxon melalui program spss dengan kemaknaan $\alpha=5 \%(0.05)$. Hasil analisis bivariat didapatkan $b=0,000$. Karena nilai kurang dari $p<\alpha$ $=0,05$ bahwa ada pengaruh senam prolanis terhadap penurunan kadar gula darah penderita diabetes melitus pada lansia di puskesmas binuang, polman. Simpulannya adalah senam prolanis mempunyai pengaruh terhadap penurunan kadar gula darah pada pasien diabetes melitus.
\end{abstract}

\section{Kata Kunci : Diabetes Melitus Tipe 2, Penurunan Kadar Gula Darah, Senam Prolanis}

\section{PENDAHULUAN}

Diabetes adalah penyakit kronis progresif yang ditandai dengan peningkatan kadar glukosa darah. Diabetes dapat menyebabkan komplikasi seperti penyakit kardiovaskular, kerusakan pada mata, ginjal dan saraf, dan kematian dini. Secara global, lebih dari 400 juta orang dewasa hidup dengan diabetes, dan diabetes secara langsung menyebabkan 1,6 juta kematian pada tahun 2015. Mengontrol glukosa darah memiliki peran penting dalam mencegah perkembangan komplikasi pada diabetes tipe 1 dan tipe 2 (WHO, 2018).

Umumnya diabetes orang dewasa hampir 90\% masuk diabetes tipe 2. Dari jumlah tersebut dikatakan bahwa 50\% adalah pasien berumur lebih dari 60 tahun. Kita menyadari bahwa penyakit diabetes tidak hanya sekedar adanya kenaikan konserasi glukosa darah atau hiperglikemia. Selain terjadi gangguan metabolisme gula pada pasien diabetes mengalami juga gangguan metabolisme lipid, sering disertai kenaikan berat badan sampai terjadinya obesitas dan tidak sedikit pula timbul gejala hipertensi (Setiati, 2014).

Menurut Atlas Diabetes edisi ke-8 Tahun 2017 dari International Diabetes
Federation menyebutkan bahwa dari catatan 220 negara di seluruh dunia, jumlah penderita Diabetes Melitus sebanyak 425 juta. Diperkirakan naik menjadi 629 juta pada tahun 2045. Hampir setengah dari angka tersebut berada di Asia, terutama China, Pakistan, dan Indonesia.

Berdasarkan data profil kesehatan Sulawesi Barat tahun 2014 DM berada dibawa hipertensi yaitu $23.12 \%$ yang dominan di derita 78\% perempuan, dan pada tahun 2015 DM berada pada angka 11,25 \% yang berkunjung ke puskesmas, pada tahun 2016 penderita DM yang berkunjung ke Rumah Sakit Umum Polewali Mandar sebanyak 1.883 Pasien sedangakan yang berkunjung ke Puskesmas sebanyak $28,30 \%$ dari semua kunjungan (Polman, 2016) .

Menurut hasil wawancara dengan $\mathrm{Hj}$. Harmawati, S.St pada hari jumat tanggal 26 Oktober 2018 selaku penanggung jawab Prolanis di Puskemas Binuang, jadwal latihan senam Prolanis seiap hari Sabtu. Latihan dilakukan di pagi hari dimulai pukul 07.00 WITA - sampai selesai. Jumlah anggota yang terdata sebanyak 60 orang dengan jumlah anggota laki-laki 14 orang dan perempuan 46 orang. Sedangkan yang aktif mengikuti senam Prolanis berkisar $80 \%$ dari jumlah anggota 
yang ada yaitu berkisar 45-50 orang, banyak yang memiliki pekerjan lain selain dari aktif senam, anggota yang berusia 70 tahun keatas gerak, daya ingat, dan kekuatan terkadang terhambat motorik yang sudah kurang peka lagi terhadap gerak senam seperti senam prolanis. Terkadang orang melakukan senam asal melakukan tanpa melihat kaidah gerakan senam yang benar. Maka senam yang dilakukan tidak membuat orang itu sehat melainkan bisa menyebabkan orang tidak sehat karena otot yang salah gerak. Meskipun banyak anggota yang berusia lanjut, tetapi semangat untuk berlatih masih terlihat dengan mengikuti latihan rutin tiap minggu dan sebagian besar lansia yang ikut prolanis di Puskesmas Binuang tidak mengomsumsi obat diabetes.

Berdasarkan uraian di atas bahwa senam prolanis dapat digunakan sebagai salah satu metode untuk menurunkan kadar gula darah, inilah yang menjadi salah satu ketertarikan penulis untuk meneliti dengan judul "pengaruh senam prolanis terhadap penurunan kadar gula darah penderita diabetes mellitus pada lansia".

\section{BAHAN DAN METODE}

\section{Lokasi, populasi dan sampel}

Penelitian ini dilakukan di Puskesmas Binuang, Polman pada tanggal 14 November s/d 14 Desember 2019. Populasi pada penelitian ini berjumlah 34 responden dan sampel berjumlah 30 responden

1. Kriteria Inklusi
a. Lansia
b. Penderita Diabetes Meliitus tipe 2
c. Bersedia di teliti
d. Lansia yang tidak mengkonsumsi obat penurun kadar gula darah
e. Terdaftar dalam kegiatan senam prolanis.

2. Kriteria Ekslusi
a. Lansia penderita DM yang tidak aktif dalam melaksanakan senam prolanis selama 4 minggu.
b. Terdapat keadaan atau penyakit lain yang mengganggu pengukuran maupun interprestasi hasil seperti hipertensi.

\section{Pengumpulan Data}

Data yang diambil dalam penelitian ini adalah data primer. Data yang dikumpulkan dengan wawancara langsung dengan melakukan observasi. Pelaksanaan penelitian ini diawali dengan penentuan sampel yang terdaftar dalam senam prolanis dengan cara menandatangani lembar persetujuan respnden ang sebelumnya telah diberikan penjelasan / informed consent mengenai tata cara penelitian ini.

\section{Pengolahan Data}

1. Editing

Editing dilakukan untuk meneliti setiap daftar pertanyaan yang sudah diisi, editing meliputi kelengkapan pengisian, kesalahan pengisian, dan konsisten dari setiap jawaban.

2. Coding

Coding merupakan tahap selanjutnya dengan member kode pada jawban dari responden tersebut. Setelah semua kuisioner diedit atau disunting, selanjutnya dilakukan peng "kodean" atau "coding" yakni mengubah data berbentuk kalimat atau huruf menjadi data atau data angka atau bilangan. Coding atau pemberian kode ini sangat berguna dalam memasukkan data (data entry).

3. Tabulasi Data

dan Setelah dilakukan kegiatan editing mengelompokkan data ke dalam suatu tabel menurut sifat-sifat yang dimiliki sesuai tuntutan penelitian.

Analisa Data

1. Analisis univariat

Analisis univariat pada umumnya dalam analisis ini menghasilkan distribusi frekuensi dan presentase dari tiap variabel (Notoadmodjo, 2014)

2. Analisis bivariat

Analisis bivariat yang dilakukan terhadap dua variabel yang diduga berhubungan atau berorelasi (Notoadmojo, 2014)

\section{HASIL PENELITIAN}

1. Analisis Univariat

Tabel 1 Distribusi Karakterisik Responden Penderita DM tipe 2 di Puskesmas Binuang, Polman.

\begin{tabular}{|c|c|c|}
\hline Karakteristik & $\mathrm{n}$ & $\%$ \\
\hline Usia & & \\
$49-59$ & 10 & 33.3 \\
$60-74$ & 15 & 50.0 \\
$75-90$ & 5 & 16.7 \\
\hline Jenis Kelamin & & \\
Perempuan & 21 & 70.0 \\
Laki-laki & 9 & 30,0 \\
\hline
\end{tabular}

Pada tabel 1 diperoleh bahwa sebagian besar responden berusia antara 49-59 tahun yaitu sebanyak 15 orang (33.3\%), kemudian responden pada rentan usia 60-74 tahun sebanyak 15 orang $(50.0 \%)$, usia $75-90$ tahun sebanyak 5 
orang (16.7\%).Dan diperoleh bahwa sebagian besar reponden berjenis kelamin perempuan dengan 21 orang. Dan laki laku berjumlah 9 orang.

Tabel 2 Distribusi Berdasarkan Rerata Kadar Gula Darah Penderita Diabetes Melitus Tipe 2 pada lansia Sebelum Senam Prolanis di Puskesmas Binuang, Polman.

\begin{tabular}{|c|c|c|c|c|}
\hline $\begin{array}{c}\text { Vari } \\
\text { abel }\end{array}$ & Mean & SD & Min-Max & $\mathrm{n}$ \\
\hline 1 & 171.93 & 42.572 & $105-293$ & 30 \\
\hline 2 & 187.50 & 87.414 & $96-461$ & 30 \\
\hline 3 & 197.33 & 75.098 & $85-380$ & 30 \\
\hline 4 & 181.17 & 52.403 & $100-292$ & 30 \\
\hline
\end{tabular}

Tabel 2 menunjukkan bahwa rata rata nilai kadar gula darah pre tes pada pasien diabetes melitus di wilayah kerja Puskesmas Binuang, Polman pada minggu pertama 171.93, minggu kedua 187.50, minggu ketiga 197.33, dan minggu keempat 181.17. Standar Deviasi pada minggu pertama 42.572, pad minggu kedua 87.414, minggu ketiga 75.098, dan minggu keempat 52.403. Adapun nilai kadar gula darah terendah yang dimiliki responden pada minggu pertama yaitu 105, minggu kedua 96, minggu ketiga 85 , dan minggu keempat 100. Dan nilai kadar gula darah tertinggi yaitu pada minggu pertama 293, minggu kedua 461, minggu ketiga 380, dan minggu keempat 292.

Tabel 3 Distribusi Berdasarkan Rerata Kadar Gula Darah Penderita Diabetes Melitus Tipe 2 pada lansia Setelah Senam Prolanis di Puskesmas Binuang, Polman.

\begin{tabular}{|c|c|c|c|c|}
\hline $\begin{array}{c}\text { Varia } \\
\text { bel }\end{array}$ & Mean & SD & $\begin{array}{c}\text { Min- } \\
\text { Max }\end{array}$ & N \\
\hline 1 & 158.37 & 41.429 & $95-282$ & 30 \\
\hline 2 & 162.27 & 66.349 & $82-321$ & 30 \\
\hline 3 & 172.10 & 67.493 & $80-367$ & 30 \\
\hline 4 & 155.20 & 46.905 & $80-258$ & 30 \\
\hline
\end{tabular}

Tabel 3 menunjukkan bahwa ratarata nilai kadar gula darah post tes pada pasien diabetes melitus di wilayah kerja Puskesmas Binuan, Polman pada minggu pertama 158.37, minggu kedua 162.27, minggu ketiga 172.10, dan minggu keempat 155.20. Standar Deviasi pada minggu pertama 41.429, pad minggu kedua 66.349, minggu ketiga 67.493, dan minggu keempat 46.905. Adapun nilai kadar gula darah terendah yang dimiliki responden pada minggu pertama yaitu 95 , minggu kedua 82 , minggu ketiga 80 , dan minggu keempat 80 . Dan nilai kadar gula darah tertinggi yaitu pada minggu pertama
282, minggu kedua 321 , minggu ketiga 367 , dan minggu keempat 258.

\section{Analisis Bivariat}

Tabel 4 Uji Wilcoxon Perbedan Nilai Kadar Gula Drah Pretest dan Posttest Senam Prolanis pada pasien Diabetes Melitus Tipe 2 Di Puskesmas Binuang, Polman

\begin{tabular}{|c|c|c|c|c|c|}
\hline \multirow{3}{*}{$\mathrm{M}$} & Pre & Post & Z- & SE & $P$ \\
\cline { 2 - 5 } & $\begin{array}{c}\text { Mean+ } \\
\text { SD }\end{array}$ & $\begin{array}{c}\text { Mean+ } \\
\text { SD }\end{array}$ & $\begin{array}{c}\text { Z- } \\
\text { scor } \\
\text { e }\end{array}$ & & \\
\hline 1 & $171.93 \pm$ & 158.37 & - & 1.45 & 0.00 \\
& 42.572 & \pm 41.42 & 4.70 & 8 & 0 \\
& & 9 & 8 & & \\
\hline 2 & $187.50 \pm$ & 162.27 & - & 5.51 & 0.00 \\
& 87.414 & \pm 66.34 & 4.78 & 6 & 0 \\
& & 9 & 4 & & \\
\hline 3 & $197.33 \pm$ & 172.10 & - & 6.17 & 0.00 \\
& 75.098 & \pm 67.49 & 4.62 & 3 & 0 \\
& & 3 & 8 & & \\
\hline 4 & $181.17 \pm$ & 155.20 & - & 3.56 & 0.00 \\
& 52.403 & \pm 46.90 & 4.78 & 4 & 0 \\
& & 5 & 4 & & \\
\hline
\end{tabular}

Tabel 4 menunjukkan bahwa hasil uji wilcoxon signet rank test diperoleh perbrdaan hasil kadar gula darah pre-test dan post-test denga hasil rata - rata pengukuran kadar gula darah pre-test minggu I $171.93 \mathrm{mg} / \mathrm{dl}$ dengan standar deviasi 45.572 dan standar eror 1.458, minggu II $187.50 \mathrm{mg} / \mathrm{dl}$ dengan standar deviasi 87.414 dan standar eror 5.516, minggu III $197.33 \mathrm{mg} / \mathrm{dl}$ dengan standar deviasi 75.098 dan standar eros 6.173, dan minggu IV $181 \mathrm{mg} / \mathrm{dl}$ dengan standar deviasi 52.403 dengan standar eror 3.564. Berdasarkan hasil uji wilcoxon signet rank test didapatkan nilai $p$ value $0.000<0.05$ (a), maka $\mathrm{H} 1$ diterima dan $\mathrm{H} 0$ ditolak berarti adanya pengaruh senam prolanis terhadap penurunan kadar gula darah penderita Diabetes melitus Tipe 2 pada lansia di wilayah kerja Puskesmas Binuang, Polman.

\section{PEMBAHASAN}

Berdasarkan

hasil

diatas menggambarkan bahwa pada hasil penelitian menunjukkan ada pengaruh yang signifikansi antara senam prolanis terhadap penurunan kadar gula darah penderita diabetes mellitus pada lansia, bahwa dari keseluruhan sebanyak 30 responden sebelum diberikan perlakuan (pretest) mengukur kadar gula darah menunjukkan minggu pertama 171.93, minggu kedua 187.50, minggu ketiga 197,33 dan minggu ke empat. Dan setelah senam prolanis didapatkan hasil minggu pertama 158.37, minggu kedua 162.27 , minggu ketiga 172.10 dan minggu keempat 155.20 . 
Sejalan dengan penelitian Nugraha, Kusnadi \% Subagjo (2016) berdasarkan uji wilcoxon dengan nilai $p=0,000$ menunjukkan adanya pengaruh senam diabetes terhadap penurunan kadar gula darah.

Berdasarkan penelitian Anggraini sri sulistyowati (2017) bahwa rata-rata kadar gula darah pre-test sebesar $182,38 \mathrm{mg} / \mathrm{dl}$ dan posttest mengalami penurunan menjadi sebesar $142,94 \mathrm{mg} / \mathrm{dl}$. Nilai kadar gula darah yang rendah ini menggambarkan terjadinya perbaikan nilai kadar gula darah setelah dilakukan senam. Penurunan kadar gula darah menunjukkan terjadinya penurunan tingkat gangguan diabetes, karena tingkat keparahan diabetes melitus akan ditunjukkan dengan adanya kadar gula darahyang semakin tinggi melebihi ambang batas normal.

\section{KESIMPULAN}

Berdasarkan hasil penelitian tentang pengaruh senam prolanis terhadap penurunan kadar gula darah penderita diabetes mellitus pada lansia di puskesmas binuang, polman maka disimpulkan bahwa ada pengaruh senam senam prolanis terhadap penurunan kadar gula darah penderita diabetes mellitus pada lansia di puskesmas binuang, polman dimana dalam hal ini senam prolanis mampu memberikan perubahan penurunan kadar gula darah penderita diabetes melitus tipe 2 .

\section{SARAN}

1. Bagi Sarana Pelayanan Kesehatan

Untuk institusi pelayanan keperawatan di puskesmas dapat membuat kebijakan bahwa senam Prolanis ini merupakan salah satu penanganan nonfarmakologik yang terdapat standar operasional prosedur penanganan pasien dengan Diabetes Melitus tipe 2.

2. Bagi Penelitian

Untuk institusi pendidikan keperawatan dapat membekali mahasiswanya sebagai calon perawat dengan memasukkan Senam Prolanis pada materi pembelajaran pada sistem endoktrin sehingga mahasiswa memiliki pengetahuan dan keterampilan yang baik dalam Senam Prolanis ini.

3. Bagi peneliti Selanjunya

Untuk penelti selanjutnya, peneliti menyarankan agar dapat menambahkan jumlah sampel penelitian sebagai kelompok control dan lebih mengontrol semua faktor yang dapat mempengaruh Diabetes Melitus Tipe 2 pada responden misalnya mengontrol masalah penyakit komplikasi yang diderita oleh resonden, faktor genetik responden, pengaturan pola makan responden dan berat badan responden.

\section{DAFTAR PUSTAKA}

Anggraeni, V., \& Rachmawati, M. R. (2018). Tidak Terdapat Hubungan Antara Akivitas Fisik Dengan Kadar Gula Darah Pada Lanjut Usia Di Panti Sosial. Jurnal Biomedika dan Kesehatan .

IDF. (2017). IDF Diabetes Atlas Eighth edition 2017. Internaional Diabetes Federation .

Notoadmodjo,S (2014) Metodologi Penelitian Kesehatan, Jakarta: PT.Rineka Cipta

Nugraha, A., Kusnadi, E., \& Subagja, S. (2016). Kadar Gula Darah Sebelum dan Sesudah Melakukan Senam Diabetes pada Pasien Diabetes Melitus Tipe II. Jurnal IImih Kesehatan .

Nursalam. (2017). Meodologi Penelitian Ilmu Keperawatan : Pendekatan Praktis Edisi 3. Jakarta: Salemba Medika.

Polman, D. (2016). profil keshatan polewali mandar. polewali: pemkot polman.

Setiati, S. (2014). Buku Ajar IImu Penyakit Dalam Edisi Keenam Jilid II . JI. Diponegoro 71 Jakarta Pusat 10430: InternalPublishing.

WHO. (2018). Guidelines on second and third line medicines and type of insulin for the control of blood glucose levels in non pregnant adults with diabete melitus. World Health Organization 